UDC 17

Susanna DAVTYAN,

Tatevik PIRUMYAN

\title{
THE PROBLEMS OF HUMAN DIGNITY AND HUMAN RIGHTS IN THE CONTEXT OF BIOETHICS
}

\begin{abstract}
The article presents an analysis of the principles of human dignity and human rights from the viewpoint of bioethics, describes the development and modifications of the concepts of "human dignity" and "human rights" in different historical stages. The authors offer detailed observation of these principles in order to have a complete and true perception of this problem and realise the role and value of these principles in the contemporary world and human relationships. For the implementation of abovementioned purposes, the paper deals with different international documents and declarations: the UNESCO Universal Declaration on Bioethics and Human Rights, the Nuremberg Code, the Declaration of Helsinki, the Declaration of Geneva, the Universal Declaration of Human Rights, the European Convention on Human Rights, the WMA Declaration of Lisbon on the rights of the patient and the Convention of Human Rights and Biomedicine.
\end{abstract}

Keywords: human dignity, human rights, informed consent, medical experiments, ethics, bioethics.

In social, political, philosophical, moral and legal thoughts the principles of human dignity and human rights are "eternal problems". These principles have a great scientific, philosophical, social, practical and theoretical significance in all development stages of history and civilisations. Human dignity acts as an integral part of the existence and development of a person and has a dynamic character. The development and progress of society and culture is impossible without full-fledged human personality with a sense of self-worth, dignity, freedom and rights. The society's and state`s task is to ensure human dignity and human rights and emphasise the significance of these principles.

There are several concepts of human digni- ty. Each era has its interpretation of principles of human dignity and human rights. In Ancient Greek philosophy, especially of Aristotle and the Stoics, dignity was associated with freedom, strong will and the ability to control himself/herself. Stoics consider that the supreme good for a man is happiness, but as in the universe everything happens by the will of the destiny, including human actions, person cannot enjoy his/her life. In this sense, a person is not born for enjoyment. Life is full of afflictions and disasters, and man should always be ready to face them. Only the wise man can overcome the different difficulties of life. According to Stoics, the wise man is characterized by four virtues: bravery, justice, moderation and intelligence. Human 
beings possess the capacity for reason and selfconsciousness. For a human being, self-preservation is not merely a matter of preserving the body but, more importantly, of preserving the mind, as our identity is strongly associated with our sense of self-consciousness and our capacity to think (Robertson, 2010, pp. 80-81). As everything in the world is predetermined, human beings must consciously obey that need by limiting their freedom. In this sense, the highest form of freedom is facing the challenges of life. If everything is predetermined and nothing can be changed, then the highest human freedom and dignity must be conditioned by a strong will.

The modern concept of human dignity begins to form in the period of Renaissance and ends in the Age of Enlightenment. Dignity is one of the main characteristics of a person or things with their intrinsic values corresponding to their purpose. If in the previous centuries, especially in the Middle Ages, human dignity is considered to be an achievement and predetermined by the creation of human beings in the image of God, the new European perceptions perceive dignity as a human characteristic. In philosophical and political thoughts of Modern times, the idea of human dignity is closely associated with the concept of human rights. In modern philosophy, dignity is interpreted not as a human being whom God created but mainly with the following terms: rationality, freedom of judgment, right to choice, practical self-determination, creativity, personal autonomy. Recognition of human dignity as an individual implies respect to basic human rights, confidentiality and identity.

In different philosophical ideas, the principles of human dignity and human rights were presented as the basic characteristic of individual freedom. Italian Renaissance philosopher Giovanni Pico della Mirandola thought that freedom and dignity are important preconditions for each person's own creation. Man is in the centre of the universe and must form himself/herself as a "free specialist". The type, place and role of human beings in the space hierarchy should be exclusively conditioned be his/her own free and responsible choice. In the book of "Oration on the Dignity of a Man" he mentioned that God has not determined the place and the role of human beings in the space hierarchy and wrote: "We have given you, oh Adam, no visage proper to yourself, nor any endowment properly your own, in order that whatever place, whatever form, whatever gifts you may, with premeditation, select, these same you may have and possess through your judgment and decision. The nature of all other creatures is defined and restricted within laws which We have laid down; you, by contrast, impeded by no such restrictions, may, by your own free will, to whose custody We have assigned you, trace for yourself the lineaments of your own nature" (Pico della Mirandola, 1956, p. 7).

$18^{\text {th }}$ century (the Age of Enlightenment) German philosopher Immanuel Kant considered that human dignity and morality are related to human free actions. Moral persons are free in their actions. According to I. Kant the principles of morality cannot be derived from experience, morality is self-sufficient (autonomous), it does not depend on empirical reality, religion and other external factors and acts only by its own laws. The laws of morality, like laws of science, have universal and necessary character. True moral actions are not caused by any factor but are done for the sake of universal moral law. Moral laws have universal importance and are mandatory for all persons. The practical principles of ethics I. Kant divided into two groups: maxims and laws. He defines maxim as a subjective principle of 
willingness, which is important only for the individual but the law has a universal meaning and is mandatory for everybody. This law I. Kant calls "Imperative", which is the basic idea of I. Kant's ethics He differentiates two types of Imperative: Hypothetical and Categorical. Hypothetical Imperative depends on external conditions and subjective motives; Categorical Imperative is objective, and the basis of it is the respect for universal moral law. Moral law (Categorical Imperative) requires that everybody should act only according to that maxim, whereby he/she can at the same time will that it should become a universal law. According to I. Kant, the moral law is possible only in the case if there is an absolute value or purpose, such as an individual. In this sense, a Categorical Imperative requires to treat a person as a purpose and not as a means. The main feature of individual is ethical autonomy, which is the basis of human dignity. It helps a person to maintain his/her dignity and this is the true motive of practical reason, the real moral law. Respect for the moral law is, therefore, the only and the undoubted moral motive, and this feeling is directed to no object, except on the ground of this law (Kant, 2004, pp. 70-85).

The principles of human dignity and human rights are the basic principles of different international documents and declaration.

In Article 3 (Human dignity and Human rights) of the Universal Declaration on Bioethics and Human Rights ${ }^{1}$ the principle of respect for human dignity directly proclaimed as a principle of doctors and researchers actions. The article claims.

- Human dignity, human rights and funda-

The Universal Declaration on Bioethics and Human Rights adopted by the General Conference of UNESCO in October 19, 2005. mental freedoms are to be fully respected.

- The interests and welfare of the individual should have priority over the sole interest of science or society (The UNESCO Universal Declaration on Bioethics and $\mathrm{Hu}-$ man Rights, 2009, p. 91).

This principle is detailed and developed mainly in Articles 4 to 15 of the declaration.

The formulation of the principle of human dignity in the Universal Declaration on Bioethics has a mutual connection with the Universal Declaration of Human Rights. According to the first article of this declaration: "All human beings are born free and equal in dignity and rights. They are endowed with reason and conscience and should act towards one another in a spirit of brotherhood" (Universal Declaration of Human Rights, 2015, p. 4) ${ }^{2}$.

In the Article 1 of the Convention of $\mathrm{Hu}-$ man Rights and Biomedicine mentioned: "Parties to this Convention shall protect the dignity and identity of all human beings and guarantee everyone, without discrimination, respect to their integrity and other rights and fundamental freedoms with regard to the application of biology and medicine" (Convention of Human Rights and Biomedicine, 1997, p. 2).

According to the first article of the European Convention on Human Rights (Obligation to respect Human Rights): "The High Contracting Parties shall secure to everyone within their jurisdiction the rights and freedoms defined in Section I of this Convention" (European Convention on Human Rights, 2010, p. 6).

The Universal Declaration of Human Rights remains as urgent nowadays. It was proclaimed in 1948 and adopted by the United Nations General Assembly. The Declaration is a normative document that, for the first time, represented the human rights, dignity and freedoms to which all human beings equal in dignity and rights. 
The principle of human dignity is also closely related to the biomedical practice and research.

- All people are equal in dignity, regardless of gender, age, social status or nationality.

- The recognition of human dignity presupposes real respect for his right to care for the inviolability of his frequent life, protection from unreasonable intrusions and respect for his public space.

Specifically, the problem of privacy is treated in the Universal Declaration on Bioethics and Human Rights, Article 9 (Privacy and confidentiality), which proclaimed: "The privacy of the persons concerned and the confidentiality of their personal information should be respected to the greatest extent possible, such information should not be used or disclosed for purposes other than those for which it was collected or consented to consistent with international law, in particular, international human rights law" (The UNESCO Universal Declaration on Bioethics and Human Rights, 2009, p. 165).

- The interests of the individual should be highly regarded in the interests of science and society. People should not become victims of scientific discoveries, as happened in many countries, for example, mass distractions in Japan at the end of World War II, except for the imminent dangers threatening society, such as mass epidemics.

This is a critical issue: it must be stated in the law:

- Who has the right to decide to harm people for saving other people and societies?

- The decision-making of these procedure control over decision making.

In the context of ethical norms, this issue implies to treat other people as a means and not as a purpose. A person is constantly involved in a relationship with other people, social groups and organizations in which he/she can be perceived as a means. At the same time he/she can treat others as a means. Here the problem is "What is the accessibility limit to treat people as a means?"

- The concept of human dignity is fundamental and it cannot be identified with human functional characteristics such as ability of decisions making or independently acting. This statement is treated in the Article 5 of Declaration (Autonomy and individual responsibility): "The autonomy of persons to make decisions, while taking responsibility for those decisions and respecting the autonomy of others, is to be respected. For persons who are not capable of exercising autonomy, special measures are to be taken to protect their rights and interests" (The UNESCO Universal Declaration on Bioethics and Human Rights, 2009, p. 111).

In medical practice recognition of human dignity as per his/her death criteria, is essential.

- Surely, in different cultures, in different religious human dignity can be interpreted in different ways. It is interpreted in various ways in different types of societies (traditional or conservative, contemporary, democratic and totalitarian). Both the Universal Declaration on Bioethics and Human Rights and the Universal Declaration on Human Rights are interpreted human dignity and human rights as a privilege values.

This statement is treated in the Article 12 of Universal Declaration on Bioethics and Human Rights (Equality, justice and equity): "The importance of cultural diver- 
sity and pluralism should be given due regarded. However, such considerations are not to be invoked to infringe upon human dignity, human rights and fundamental freedoms nor upon the principles set out in this Declaration, not to limit their scope" (The UNESCO Universal Declaration on Bioethics and Human Rights, 2009, p. 199).

- A person has the right to be respected by others for his/her own dignity which means that everyone must respect the right of the dignity of others and supposes not to harm, not to obligate others your opinion or not to treat others as a means and not as a purpose.

The Universal Declaration on Bioethics and Human Rights is a generalized normative document that represents the basic principles concerning the moral side of biomedical researches and practice. The political possibilities of such an international document, as this declaration, were used precisely to clearly articulate the rights of a person-patient or "study subjects" in biomedical researches and practice. The declaration summarizes not only active researches and development in the field of bioethics but also continues and develops the work that the famous Nuremberg Code (1947) began. After World War II the Nuremberg Tribunal discovered the horrible and inhuman medical experimentations on war prisoners of Nazi Germany by Nazi physicians. After these incidents, the Nuremberg Code was formed. The basic principles of Nuremberg Code are informed consent of human subjects that participate in the experiments, scientific and humanitarian validity of the medical experimentations, the possible risk from the participation of the human subject in the medical experimentations and the potential benefits of it, protecting the health, well-being and human dignity of the study subjects, etc. Physician or researcher must inform the human subject about purpose, nature, duration, results as well as possible risks of experimentations. The human subject has the right to refuse or accept experimentations after getting information (The Nuremberg Code, 1947).

The Nuremberg Code is the first international complete set of rules about experiments conducted on people. The atrocities perpetrated by the Nazis more than half a century ago may be the most prominent human rights abuses in the global consciousness; nonetheless torture and other inhumane act still widely carried out today. Torture is practised in over 150 countries and has even been seen as a necessary evil in the global "war and terror" (Michael Grodin and George Annas, 2007, p. 650). The tragic experience of the mid- $20^{\text {th }}$ century, associated with biomedical researches and forced participation of people, has become a very effective impetus for ethical rethinking about the role of scientists in the life of society, about their civil and moral responsibility for the consequences of scientific research and development. The Nuremberg Code was formed during Nuremberg trials on Nazi Germany doctors (1946-1947).

On April 17, 1947, Dr Leo Alexander submitted to the Counsel for War Crimes six points defining legitimate medical research. These six points were adopted by the trial verdict and added an extra four. The ten points constituted the "Nuremberg Code". In 1949 Leo Alexander published the article "Medical science under dictatorship" in The New England Journal of Medicine, where he mentioned that a large part of these medical experiments on war prisoners of Nazi Germany was devoted to the science of destroying and preventing life, for which he formed the 
word "ktenology", the science of killing (Leo Alexander, 1949, p. 41).

The aim of the Nuremberg Code is to preserve the world from the religious, political and cultural wars and torture, which are inevitable in the contemporary globalized and continuously changing the world. Only the acceptance of the principles of the Nuremberg Code can face the various challenges of the $21^{\text {st }}$ century, which is growing and becoming uncontrollable.

The ideas of the Nuremberg Code were developed in the Declaration of Geneva adopted by the $2^{\text {nd }}$ General Assembly of the World Medical Association in September 1948, which proclaimed the modernized version of the Hippocratic Oath. In Declaration of Geneva, the most important principles are.

- Service of humanity;

- respect the autonomy and dignity of the patient;

- maintain the utmost respect for human life; (Declaration of Geneva, 1948).

The main ideas of the Declaration of Geneva were developed in the WMA Declaration of Helsinki ethical principles for medical research involving human subjects adopted by the $18^{\text {th }}$ World Medical Association General Assembly in June 1964. According to this Declaration, it is the duty of the physician to promote and safeguard the health, well-being and rights of patients, including those who are involved in medical research. The physician's knowledge and conscience are dedicated to the fulfilment of this duty (Declaration of Helsinki, 1964).

The adoption of the Nuremberg Code and the Declaration of Geneva is urgent nowadays, especially in the context of Guatemala experiments. In 1946-1948 the United States conducted experiments in Guatemala on people-patients of psychiatric clinics, prisoners, soldiers without their informed consent. The main purpose of these experiments is to test penicillin for the treatment of sexually transmitted diseases (STD). Nearly 700 men were forcibly and secretly infected with the viruses of these diseases, and not all of them were treated with penicillin.

At the same time in the United States is created a Commission to study experience of medical research which the US is conducting abroad, to develop a mechanism that excludes the violation of ethical standards in such studies.

After a scholarly publication disclosed the existence of records of these experiments in 2010, the Presidential Commission for the study of Bioethical Issues (the Commission) conducted a detailed investigation of the events surrounding and including the experiments. In the report, "Ethically Impossible:" STD Research in Guatemala from 1946 to 1948, provides a detailed description and ethical evaluation of these studies (A Study Guide to "Ethically Impossible" STD Research in Guatemala from 1946 to 1948, 2012, p. 1).

It is very important that the indignation provokes not the fact of experiments, but how these experiments have been carried out, secretly, without informing "the study subject" about experiments, without informed consent, with the explicit threat of their health, without the need to carry out experiments especially on those people.

The problems of human dignity and human rights are closely connected to the problem of informed consent (one of the main problems of bioethics). Respect for dignity is manifested in recognition of the right of the patient or the "study-subject" to have full awareness of the intended treatment. According to the Article 6 (Consent) of the Universal Declaration on Bioethics and Human Rights: "Any preventive, di- 
agnostic and therapeutic medical intervention is only to be carried out with the prior, free and informed consent of the person concerned, based on adequate information. The consent should where appropriate, be express and may be withdrawn by the person concerned at any time and for any reason without disadvantage or prejudice" (The UNESCO Universal Declaration on Bioethics and Human Rights, 2009, p. 122).

The issues of human dignity and human rights deserve special attention in the case of persons without the capacity to consent. According to the Article 7 (Persons without capacity to consent) of above-mentioned declaration: "In accordance with domestic law, special protection is to be given to persons who do not have the capacity to consent: authorization for research and medical practice should be obtained in accordance with the best interest of the person concerned should be involved to the greatest extent possible in the decision-making process of consent, as well as that of withdrawing consent" (The UNESCO Universal Declaration on Bioethics and Human Rights, 2009, p. 139).

With regard to the problems of informed consent, human dignity and human rights, such questions often arise: How to behave in extreme situations? For example, when there is no time to get informed consent from the patient or in the case of patients without the capacity to consent, as well as in more serious situations, for instance, in the case of dying patients and palliative care, vegetative patients and finally, the specific situations are embryo and fetus. There is no common public opinion on these issues. It is obvious that the philosophical and ethical interpretation of their status and careful and caring attitude toward embryo and fetus is necessary.
According to the WMA Declaration of Lisbon on the rights of the patient ${ }^{3}$ the patient has the right to medical care of good quality care, right to freedom of choice. The patient has the right to accept or refuse appropriate medical treatment after getting information. He/she has the right of information. The doctor must fully inform the patient about his/her disease, about the methods of treatment, about the results of treatment and the possible risks of treatment (Declaration of Lisbon on the rights of the patient, 1981).

The problems of informed consent, human dignity and human rights are also treated in Article 13 of Human Rights and Biomedicine (Information and consent). The article claims.

- The persons being asked to participate in a research project shall be given adequate information in a comprehensible form. This information shall be documented.

- The information shall cover the purpose, the overall plan and the possible risks and benefits of the research project, and include the opinion of the ethics committee. Before being asked to consent to participate in a research project, the persons concerned shall be specifically informed, according to the nature and purpose of the research (Human Rights and Biomedicine, Article 13, p. 54$55)$.

Thus, the study of the principles of human dignity and human rights acquired theoretical and practical importance. The development of bioethics and the adoption of the Universal Declaration on Bioethics and Human Rights are considered to be important stages of above-mentioned processes, reflecting essential changes not

3 World Medical Association Declaration of Lisbon on the rights on patient adopted by the $34^{\text {th }}$ World Medical Assembly, Lisbon, Portugal, September/October, 1981. 
only in the medical-biological but also in ethical thinking. Due to the bioethical discussions philosophical and moral perception of the concepts of human dignity, human rights and informed consent are changed and summarized. Thanks to the concept of informed consent, understanding the concept of respect for human beings implies immediate attention of someone else's position in every critical situation. In the context of bioethics, the informed consent implies the patient's attitude towards the treatment or the participant's attitude towards the scientific experiments in which he/she should participate.

Acceptance of an informed consent assures recognition of someone else's dignity. Here we have a perceived perception of moral relationships: in ethical thoughts, an emphasis is transferred from the active person to the recipients; it means that in this case, the subject of ethical study is not the person, but the interpersonal relationship. Similar innovations are typical of other types of applied ethics also. In all cases, the significance of ethical research is disclosed and summarized, part of which is declarations. However, the fact is that some scientists and researchers do not follow the main principles of abovementioned declarations and conventions and continue their different medical and scientific experimentations. The proof is that though in 1947 the Nuremberg Code and in 1964 the Declaration of Helsinki were adopted, on June 16, 1966 Henry Beecher from Harvard Medical School published the article: "Ethics and Clinical Research" in the British New Journal of Medicine, which concentrated the society attention to the fact that numerous scientific and medical experimentations were taking place on human beings without taking into consideration the human subjects` informed consent. Our conclusion is that it is necessary to develop such methods by which it will be possible to widely spread the content of the above-mentioned declarations and conventions and more strictly follow the process of their application and preservation.

\section{REFERENCES}

Alexander, L. (1949). Medical Science under Dictatorship. The New England, Journal of Medicine, 241(2). Retrieved September 19, 2018 from:

https://www.mcgill.ca/prpp/files/prpp/1 eo alexander 1949 --medical_science_under_dictatorship. pdf.

A Study Guide to "Ethically Impossible" STD Research in Guatemala from 1946 to 1948. (2012).

Presidential Commission for the Study of Bioethical Issues, Washington, November. Retrieved September 25, 2018 from: https://bioethicsarchive.georget own.edu/pcsbi/sites/default/files/A\%2 0Study $\% 20$ Guide $\% 20$ to\%20Ethically \%20Impossible.pdf.

Convention of Human Rights and Biomedicine. Oviedo, 4. IV (1997). Retrieved September 30, 2018 from:

https://rm.coe.int/168007cf98.

Declaration of Lisbon on the Rights of Patient. (1981). World Medical Association. Retrieved September 21, 2018 from: https://www.wma.net/policiespost/wma-declaration-of-lisbon-onthe-rights-of-the-patient/.

Declaration of Geneva (1948). World Medical Association. Retrieved September 21, 2018 from:

https://www.wma.net/policiespost/wma-declaration-of-geneva/. 
Declaration of Helsinki-Ethical Principles for Medical Research Involving Human Subjects. (1964). World Medical Association. Retrieved September 22, 2018 from:

https://www.wma.net/policiespost/wma-declaration-of-helsinkiethical-principles-for-medicalresearch-involving-human-subjects/. European Convention on Human Rights. (2010). European Court of Human Rights. Council of Europe. Retrieved September 27, 2018 from:

https://www.echr.coe.int/Documents/ Convention ENG.pdf.

Human Rights and Biomedicine. The Oviedo Convention and its Protocols. Council of Europe. Information and consent. Article 13-Information for research participants. Retrieved September 28, 2018 from:

https://www.coe.int/en/boethics.

Kant, I. (2004). Critique of Practical Reason. (Th. K. Abbott, Ed.). New York: Dover Publications.

Michael, G., \& George, A. (2007, September). Physicians and Torture: Lessons from the Nazi Doctors. International Review of the Red Cross, 89(867). Retrieved September 19, 2018 from: https://pdfs.semanticscholar.org/4db0 /d37f8a282c91d06dde619e617f9538 769eae.pdf.

Pico della Mirandola, G. (1956). Oration on the Dignity of a Man. (A. Robert, Trans.). Chicago: A Gateway Edition Henry Regnery Company.

Robertson, D. (2010). The Philosophy of Cognitive-Behavioural Therapy (CBT). Stoic Philosophy as Rational and Cognitive Psychotherapy. London: Karnac Books Ltd.

The Nuremberg Code. (1947) Retrieved September 15, 2018 from:

https://history.nih.gov/research/downl oads/nuremberg.pdf.

The UNESCO Universal Declaration on Bioethics and Human Rights. (2009). Background, Principles and Application. (Henk A. M. J. ten Have, \& M. S. Jean, Ed.), Ethics series, UNESCO Publishing. Retrieved September 17, 2018 from:

http://unesdoc.unesco.org/images/00 17/001798/179844e.pdf.

Universal Declaration of Human Rights. (2015). United Nations. Retrieved September 25, 2018 from:

http://www.un.org/en/udhrbook/pdf/ udhr booklet en web.pdf. 